\title{
NUTRIENT REMOVAL CAPACITIES OF FOUR SUBMERGED MACROPHYTES IN THE POYANG LAKE BASIN
}

\author{
LIU, J. T. ${ }^{1}-$ SUN, J. J. ${ }^{2}-$ FANG, S. W. $.^{1 *}-$ HAN, L. ${ }^{3}-$ FENG, Q. ${ }^{1}-$ HU, F. ${ }^{1}$ \\ ${ }^{1}$ Jiangxi key Laboratory of Poyang Lake water resources and environment, \\ Jiangxi institute of water sciences \\ 1038 East Beijing Road, Nanchang 330029, P.R.China \\ ${ }^{2}$ Jiangxi Ecological Civilization Research and Promotion Association \\ 1038 East Beijing Road, Nanchang 330029, P.R.China \\ ${ }^{3}$ AssociationColloge of environment, Hohai university \\ 1 West Xikang Road, Nanjing 330029, P.R.China \\ (phone: +86-791-8760-6580; fax: +86-791-8760-6503) \\ *Corresponding author \\ e-mail: shaowenfang6666@163.com; phone: +86-791-8760-6666 \\ (Received $2^{\text {nd }}$ Oct 2015; accepted $17^{\text {th }}$ Jan 2016)
}

\begin{abstract}
Submerged macrophytes play an important role in eutrophic water purification. Using four species of commonly submerged macrophytes, Ceratophyllum demersum, Elodea canadensis, Hydrilla verticillata and Vallisneria natans (Lour.) Hara, as research objects, and using the Junshan Lake water quality in the Poyang Lake basin as the standard, purification efficiency levels were analyzed for submerged macrophytes at low temperatures using static simulation experiments. The results showed that these four of submerged macrophyte species could partially purify eutrophic water at low temperatures. The purification efficiencies of the four submerged macrophyte species were ranked in descending order as follows: Elodea canadensis, Hydrilla verticillata, Ceratophyllum demersum, and Vallisneria natans (Lour.) Hara. For Ceratophyllum demersum, Elodea canadensis, Hydrilla verticillata and Vallisneria natans (Lour.) Hara.The maximum total nitrogen (TN) removal rates were $67.84 \%, 68.70 \%, 64.38 \%$ and 69.13\% of Ceratophyllum demersum, Elodea canadensis, Hydrilla verticillata, and Vallisneria natans (Lour.) Hara, respectively; the maximum total phosphorus (TP) removal rates were $36.59 \%, 58.60 \%$, $47.94 \%$ and $43.70 \%$, respectively; the maximum $\mathrm{NH}_{4}{ }^{+} \mathrm{N}$ removal rates were $23.86 \%, 24.69 \%, 18.47 \%$ and $22.93 \%$, respectively; the maximum $\mathrm{NO}_{3}-\mathrm{N}$ removal rates (percentage) were $46.69 \%, 41.08 \%$, $34.19 \%$ and $36.32 \%$, respectively; the maximum $\mathrm{PO}_{4}-\mathrm{P}$ removal rates were $24.26 \%, 27.92 \%, 22.75 \%$ and $12.71 \%$, respectively; and the maximum $\mathrm{COD}_{\mathrm{Mn}}$ removal rates of $35.11 \%, 45.06 \%, 46.30 \%$ and $42.88 \%$, respectively.
\end{abstract}

Keywords: submerged macrophytes, eutrophication, purification efficiency, Junshan Lake

\section{Introduction}

Currently, an important problem in aquatic environments is eutrophication that is primarily caused by high concentrations of nitrogen and phosphorus in the water column (Howarth and Marino, 2006; Carpenter, 2008; Hautier et al., 2009). Most experts believe that hydrophytes can be used to treat polluted water (Huang et al., 2005; Hu et al., 2008).

Submerged macrophytes fundamentally shape ecological productivity in lake systems. The plant species purifies a water body by absorbing, transferring and converting nitrogen, phosphate and other persistent organic pollutants into biomass in water columns and sediment. Submerged macrophytes can also inhibit biotic and abiotic suspensions, enhance illumination effects and dissolve oxygen in water by increasing 
the spatial niche. These processes provide the necessary conditions for establishing a complex food web development in aquatic ecosystems (Song and Chen, 1997). By regulating cycling speeds, enhancing biodiversity, and controlling algae growth, submerged macrophytes also improve water quality levels in water columns and ecological sediment environments. Hence, eco-restoration from submerged macrophyte is central to eutrophication control (Zhao et al., 2010; Ren et al., 2011).

Poyang Lake located in the north of Jiangxi Province and lies on the southern bank of Yangtze River in China. It is the biggest freshwater lake in China as well as one of the most important international wetlands. Although it is the lowest eutrophication of five great lakes in China, increased human activity and rapid development of the economy have led to great changes in the environment of Poyang Lake, of which eutrophication is the most serious. Poyang Lake (Fig.1), aquatic vegetation in Junshan Lake has declined gradually due to the damming of the dam and the presence of crab cultivation activities. Frequent forage flooding has compromised the eco-balance of the lake, degrading eco-system water quality and spurring eutrophication, posing a threat to water environment security of Poyang Lake. Temperature is an important factor affecting the effects of sewage treatment, because of the withering of plants and the reducing of microbial activity. At low temperature, the effect reduced (Zhang et al., 2006). Low removal rate produced by the long time low-temperature in winter of Poyang Lake becomes the key to sewage purification. Some winter growth of submerged plants can reduce the influence of the low temperature (Huang et al., 2005).

According to the survey results in 1984, the macrophytes including Vallisneria natans (Lour.) Hara and Hydrilla verticillata were dominant species, and the biomass accounted for $22.24 \%$ and $16.6 \%$ of the total biomass of the macrophytes in Poyang Lake (Guan et al., 1987). The Ceratophyllum demersum was common species in Poyang Lake, and the biomass accounted for $2.85 \%$ of the total biomass of the macrophytes in Poyang Lake (Guan et al., 1987). At the same time, Elodea canadensis was considered as pioneer submerged macrophyte for eutropihication water purification (Tian et al., 2000), this study examined the purification efficiencies of the four common submerged macrophyte species in autumn. Using the Jun-Shan Lake water quality in the Poyang Lake basin as the standards, this study also analyzed the concentrations of TN, TP, $\mathrm{NH}_{4}{ }^{+}-\mathrm{N}, \mathrm{NO}_{3}-\mathrm{N}, \mathrm{PO}_{4}-\mathrm{P}$ and $\mathrm{COD}_{\mathrm{Mn}}$ affected by submerged macrophytes, as well as their purification capacities. Though this research, we developed a theory for the selection of submerged macrophytes for eutrophication treatment and ecological recovery in Poyang Lake.

\section{Review of literature}

Submerged macrophyte is one of the primary producers of the lake ecological system (Ren et al., 2011). The ecological restoration by submerged macrophytes is an important link to control eutrophication, and such research is carried out a lot in at home and abroad (Bole and Allan, 1978; Phillips et al., 1978; Ewell, 1987; Zhao et al., 2010; Blindow et al., 2002). Ceratophyllum demersum (Wang et al., 2008; Tian et al., 2009; Ren et al., 2011), Elodea canadensis (Wang et al., 2008; Zhu et al., 2008; Tian et al., 2009 ), Hydrilla verticillata (Ren et al., 2011; Wang et al., 2008; Wang et al., 2008) and Vallisneria natans (Lour.) Hara (Sun et al., 2012) are used as the common submerged macrophytes for eutrophication water purification. For the purification, removal rate and removal capacity are taken as the indicators for measuring the purification ability of 
submerged macrophytes (Ren et al., 2011; Sun et al.,2012), and the pollution indicators are monitored such as total nitrogen (TN), total phosphorus (TP), ammonia nitrogen $\left(\mathrm{NH}_{4}{ }^{+}-\mathrm{N}\right)$, nitrate nitrogen $\left(\mathrm{NO}^{3}-\mathrm{N}\right)$ and $\mathrm{COD}$ etc. (Tian et al., 2009; Wang et al., 2008; Sun et al.,2012).

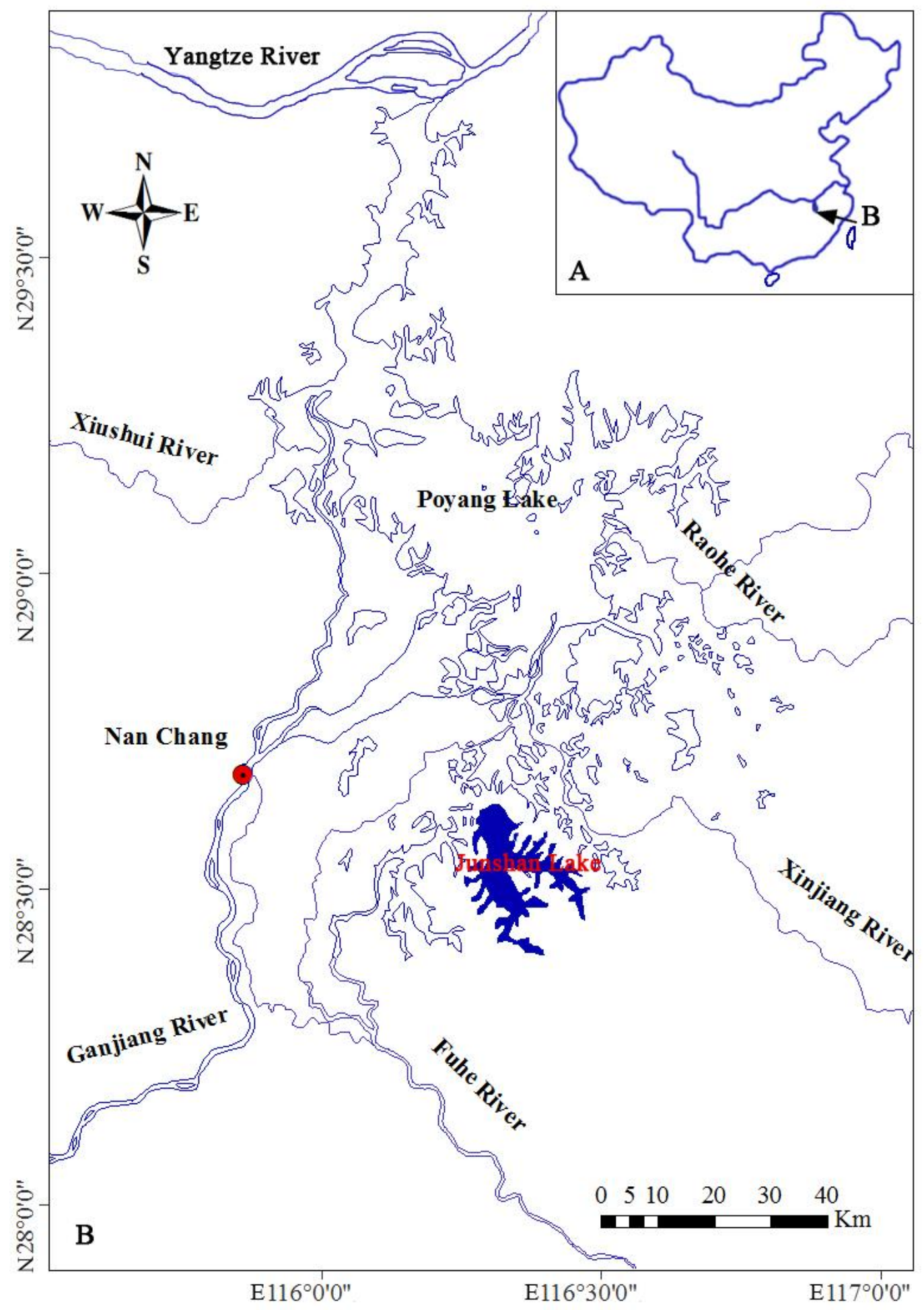

Figure 1. Location of Junshan Lake 


\section{Materials and methods}

\section{Materials}

Samples of the four submerged macrophyte species, Ceratophyllum demersum Elodea canadensis, Hydrilla verticillata and Vallisneria natans (Lour.) Hara, were collected from Chi Lake (a section of Poyang Lake basin) located in Ruichang City, Jiangxi Province, on October 16, 2012. All macrophyte samples were healthy, mature and were undergoing similar growth stages. After removing sludge and other impurities from the samples, we placed the samples into a container of a 100-dilution Hoagland nutrient solution for a 7-day acclimatization period. Then, we selected mature and healthy samples of similar growth stages.

\section{Experimental conditions and method}

All experiments were conducted from Ocbober 23, 2012 until November 26, 2012 using four submerged macrophyte species under laboratory conditions with the same water depth, and didn't use any heat preservation measures in order to keep the experimental temperature as same as the outdoor. After equipping experiment water contrasting Junshan Lake water quality and filling $30 \mathrm{~L} 2$-cm-thick plastic containers with $0.5-1.0-\mathrm{cm}$ diameter abluent quartz sand.Then we conducted experiments with and without submerged macrophytes. Three blanks and experiments were repeated with for each type of macrophyte.

To sample $500 \mathrm{ml}$ lake water $10 \mathrm{~cm}$ below the water surface via siphoning, we determined initial concentrations using an aquatic quality indicator and drew evaporation samples using fresh water. The samples were collected every 7 days. Then, we determined the aquatic chemical components, e.g., TN, TP, $\mathrm{NH}_{4}{ }^{+}-\mathrm{N}, \mathrm{NO}_{3}-\mathrm{N}, \mathrm{PO}_{4}-\mathrm{P}$ and $\mathrm{COD}_{\mathrm{Mn}}$, and these were analyzed following the method described in Rules of eutrophication invesgation in lake (Jin and Tu, 1990).

\section{Calculation method}

Removal rate $(\%)=($ initial pollutant concentration - terminal pollutant concentration $)$ / initial pollutant concentration $\times 100 \%$;

Removal capacity $\left(\mathrm{mg} \cdot \mathrm{d}^{-1} \cdot \mathrm{g}^{-1}\right)=($ initial pollutant concentration - terminal pollutant concentration) $\times$ volume $/$ days / average biomass.

\section{Results and analysis}

\section{Initial concentration and submerged macrophyte growth analysis}

Considering the current water quality levels for Poyang Lake basin, we monitored the water quality of Junshan Lake in August 2012, and the result showed that the TN, $\mathrm{TP}$ and COD were $0.75 \mathrm{mg} / \mathrm{L}, 0.075 \mathrm{mg} / \mathrm{L}$ and $5.5 \mathrm{mg} / \mathrm{L}$ respectively, which were close to eutrophication level. The water quality in Junshan Lake was taken as reference standard, and the initial concentrations of the submerged macrophytes are shown in Table 1 . 
Table 1. Individual initial concentration of four types of submerged macrophytes indicators.

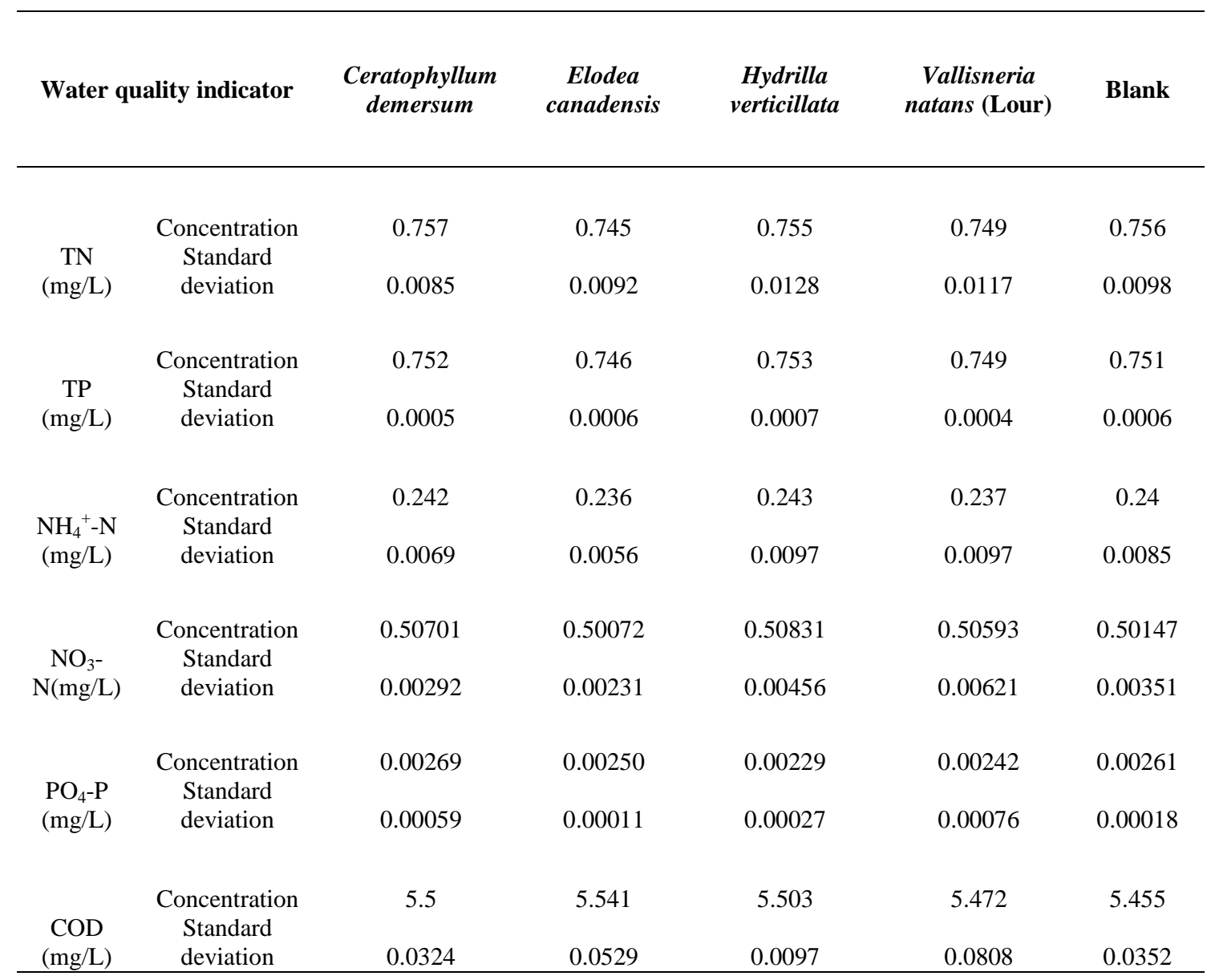

Table 2 shows limited variations in the total fresh weight levels among the Ceratophyllum demersum, Elodea canadensis, and Hydrilla verticillata samples; howerer, Vallisneria natans (Lour.) Hara had a heavier weight and was composed of $70 \%$ water. The other three samples contained $80 \%$ water.

This study was conducted from late October 2012 to November 2012. The average temperatures in October and November were recorded to be approximately $20^{\circ} \mathrm{C}$ and $13^{\circ} \mathrm{C}$, respectively. The temperature change affected the four submerged macrophyte species differently. During the experiments, Ceratophyllum demersum grew well, developing adventive roots that reached the bottom of the experimental apparatus. Using these adventive roots, the Ceratophyllum demersum sample absorbed and transferred nutrients efficiently. In a later stage of the experiments, parts of the Elodea canadensis sample died, and a similar but more pronounced phenomenon occurred in the Hydrilla verticillata and Vallisneria natans (Lour.) samples. Nearly the entire Vallisneria natans (Lour.) sample died by the end of the experiments, causing further pollution of the water body. 
Table 2. Initial wet weight, dry weight, water content and total fresh weight of four types submerged macrophytes

\begin{tabular}{ccccccc}
\hline $\begin{array}{c}\text { Submerged } \\
\text { macrophytes }\end{array}$ & $\begin{array}{c}\text { Wet } \\
\text { weight/unit } \\
(\mathbf{g})\end{array}$ & $\begin{array}{c}\text { Dry } \\
\text { weight/unit } \\
(\mathbf{g})\end{array}$ & $\begin{array}{c}\text { Water } \\
\text { content } \\
(\boldsymbol{\%})\end{array}$ & $\begin{array}{c}\text { Unit } \\
\text { (individual } \\
\text { plant) }\end{array}$ & $\begin{array}{c}\text { Length } \\
(\mathbf{c m})\end{array}$ & $\begin{array}{c}\text { Total fresh } \\
\text { weight }(\mathbf{g})\end{array}$ \\
\hline $\begin{array}{c}\text { Ceratophyllum } \\
\text { demersum }\end{array}$ & 0.3069 & 0.1194 & 0.7991 & 5 & 25 & 1.5343 \\
$\begin{array}{c}\text { Elodea canadensis } \\
\text { Hydrilla verticillata }\end{array}$ & 0.2021 & 0.0756 & 0.8133 & 5 & 21 & 1.0106 \\
$\begin{array}{c}\text { Vallisneria natans } \\
\text { (Lour) }\end{array}$ & 0.3200 & 0.0900 & 0.7188 & 3 & 17 & 0.9600 \\
\hline
\end{tabular}

\section{TN-removal efficiency of submerged macrophytes}

Because the submerged macrophytes efficiently removed TN from water bodies, we constructed a tendency chart of TN concentration change records from the four species of macrophytes submerged in water (Fig.2). Briefly, water bodies were purified to different extents under different experimental conditions. At different stages of the experiments, the plants clearly removed more TN compared with the control experiments. In the first 14 days, the TN concentrations decreased due to the presence of submerged macrophytes. In later stages of the Ceratophyllum demersum L and Hydrilla verticillata experiments, the TN concentrations in the water body decreased at a slower rate. Meanwhile, for the Elodea canadensis and Vallisneria natans (Lour.) experiments, the TN concentrations fluctuated along flexible curves. In the experiments without plants, the concentrations initially decreased but then followed a flexible wave pattern due to the absence of macrophytes.



Figure 2. Variation of TN concentration during the experiment 
The removal efficiencies of the various experimental conditions are shown in Fig.3. The removal rates for the four submerged macrophyte species were calculated as the difference between the data for the experiments with plant and control experiments. The results indicate that the $\mathrm{TN}$ removal rates accelerated as a result of submerged macrophyte purification, reaching a peak value (i.e., a minimum TN value) on the $14^{\text {th }}$ day. At this point, the removal rates of the four submerged macrophyte species approached $70 \%$. The TN removal percentages for Ceratophyllum demersum, Elodea canadensis, Hydrilla verticillata, and Vallisneria natans (Lour.) were 67.84\%, 68.70\%, $64.38 \%$, and $69.13 \%$, respectively. Hence, the TN removal efficiencies for the four submerged macrophyte species are ranked in descending order as follows: Vallisneria natans (Lour.), Elodea canadensis, Ceratophyllum demersum, and Hydrilla verticillata. After a sharp decline, the purification activity in the Ceratophyllum demersum and Hydrilla verticillata experiments became more gradual, and the curves of the Elodea canadensis and Vallisneria natans (Lour.) experiments became flexible.



Figure 3. Removal efficiency of TN during the experiment

\section{TP-removal efficiency of submerged macrophytes}

Submerged macrophytes played a critical role in TP removal through anabolism processes and by adhering to PAO (phosphorus accumulation organism) surfaces (Tian et al., 2009). Fig. 4 shows decreasing curves for the four submerged macrophyte species experiments in the first 27 days. The macrophyte experiments initially showed decreasing tendencies, but the TP concentration increased thereafter because of the dead macrophytes and restrict temperatures. The terminal data for the control experiments were higher for every period. 


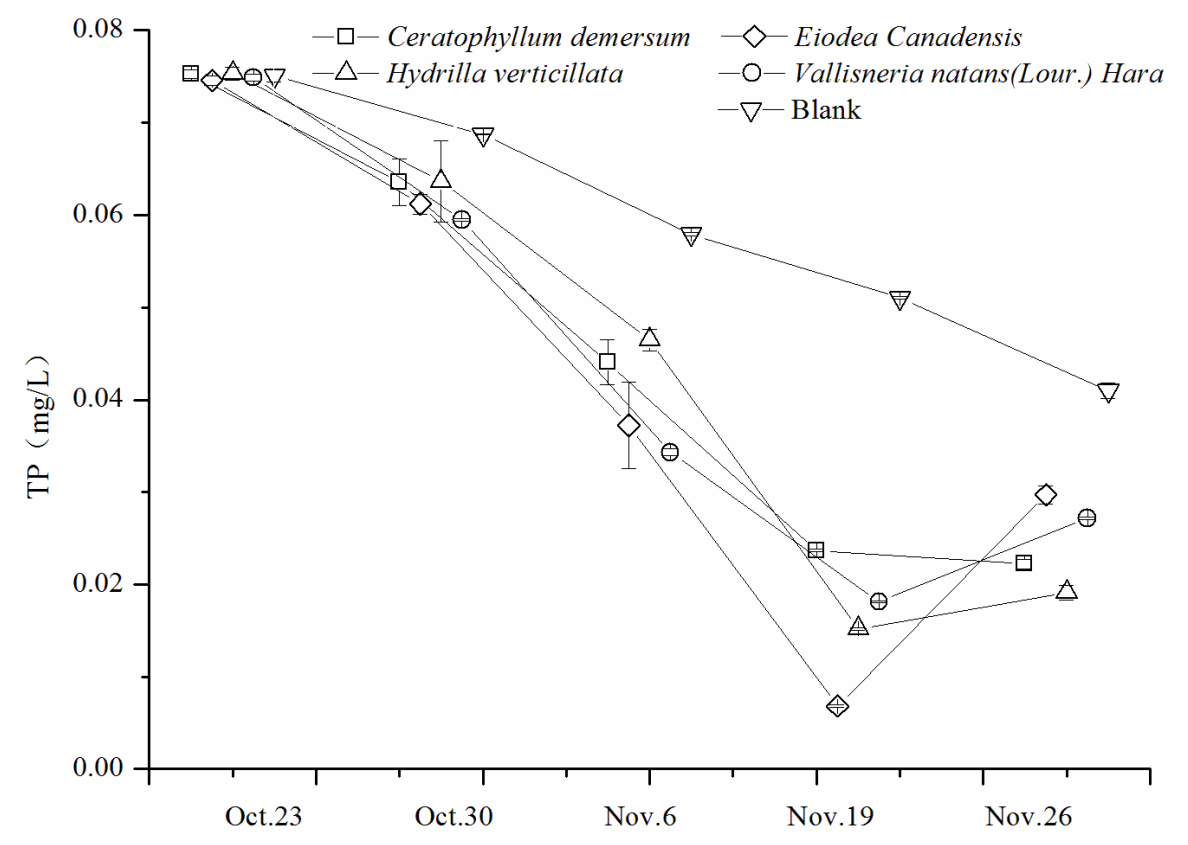

Figure 4. Variation of TP concentration during the experiment

Fig.5 shows that the TP removal rates in the control condition increased until reaching $45.38 \%$ at the end of the experiment. The submerged macrophyte removal rates were calculated as TN levels, which increased until reaching a maximum value on the $27^{\text {th }}$ day and then declined. The TP removal rates for Ceratophyllum demersum, Elodea canadensis, Hydrilla verticillata, and Vallisneria natans (Lour.) were 36.59\%, $58.60 \%, 47.94 \%$ and $43.70 \%$, respectively. Thus, the efficiency levels for the four submerged macrophyte species are ranked in descending order as follows: Elodea canadensis, Hydrilla verticillata, Vallisneria natans (Lour.) and Ceratophyllum demersum.

\section{$\mathrm{NH}_{4}^{+}$-N-removal efficiency of submerged macrophytes}

Fig.6 shows that the $\mathrm{NH}_{4}{ }^{+}-\mathrm{N}$ concentrations decreased linearly, and the values generated under the submerged macrophyte conditions were much lower than those of the control condition. Chang-Hua Tong's (2008) experiments conducted under winter conditions showed the $\mathrm{NH}_{4}{ }^{+}-\mathrm{N}$ removal efficiency values of only $14 \%-70 \%$, which indicated that $\mathrm{NH}_{4}{ }^{+}-\mathrm{N}$ could be removed via evaporation and by directly adhering to sediment (Reddy and Kevusk, 1987). However, $\mathrm{NH}_{4}{ }^{+}-\mathrm{N}$ is typically removed via nitrification and denitrification ( $\mathrm{Li}$ and $\mathrm{Hu}, 1995)$. Given the low temperature conditions used in this study, the removal efficiencies can not clearly attributable to submerged macrophytes because all values were below $25 \%$. By the $14^{\text {th }}$ day of the experiment (Fig.7), the removal rates of the submerged macrophyte attained the peak levels, with Ceratophyllum demersum, Elodea canadensis, Hydrilla verticillata, and Vallisneria natans (Lour.) reaching 23.86\%, 24.69\%, 18.47\%, and $22.93 \%$, respectively. Thus, the efficiency levels for the four submerged macrophyte species are ranked in descending order as follows: Elodea canadensis, Ceratophyllum demersum, Vallisneria natans (Lour.) and Hydrilla verticillata. Only slight differences were found among them. 


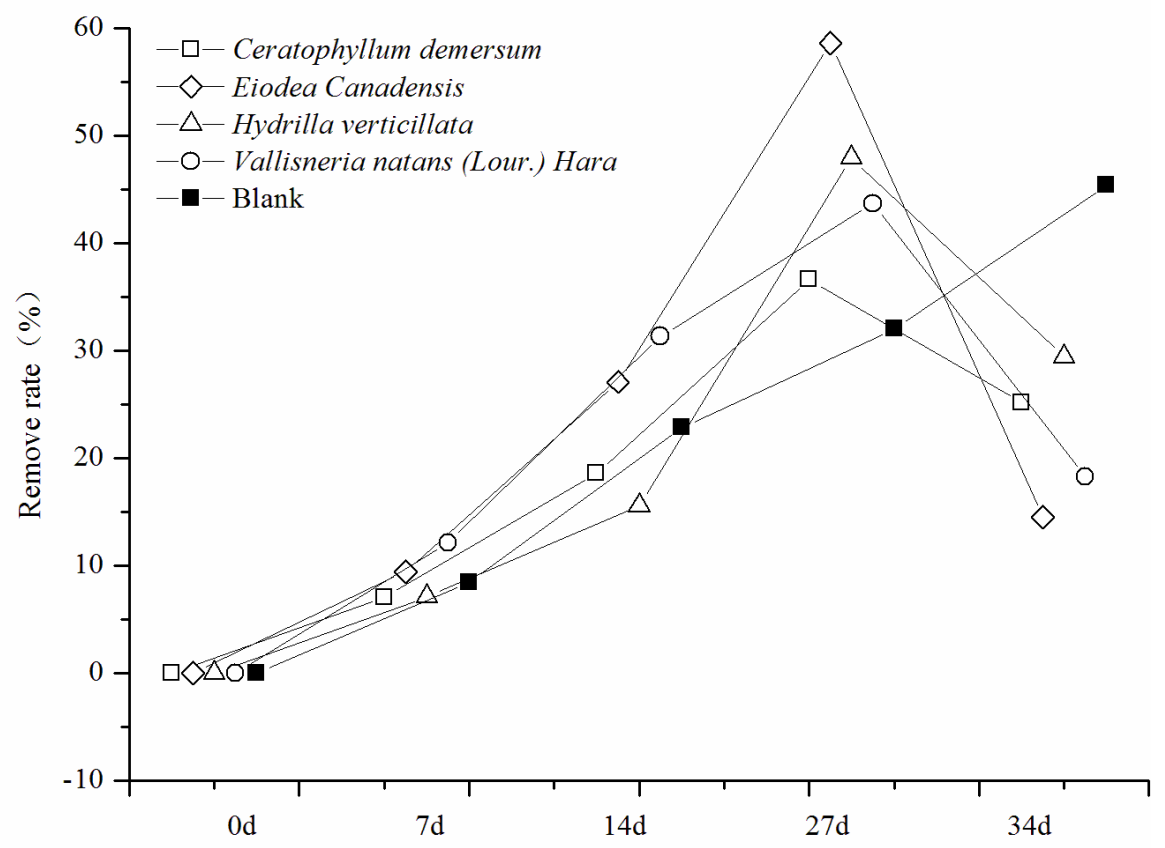

Figure 5. Removal efficiency of TP during the experiment

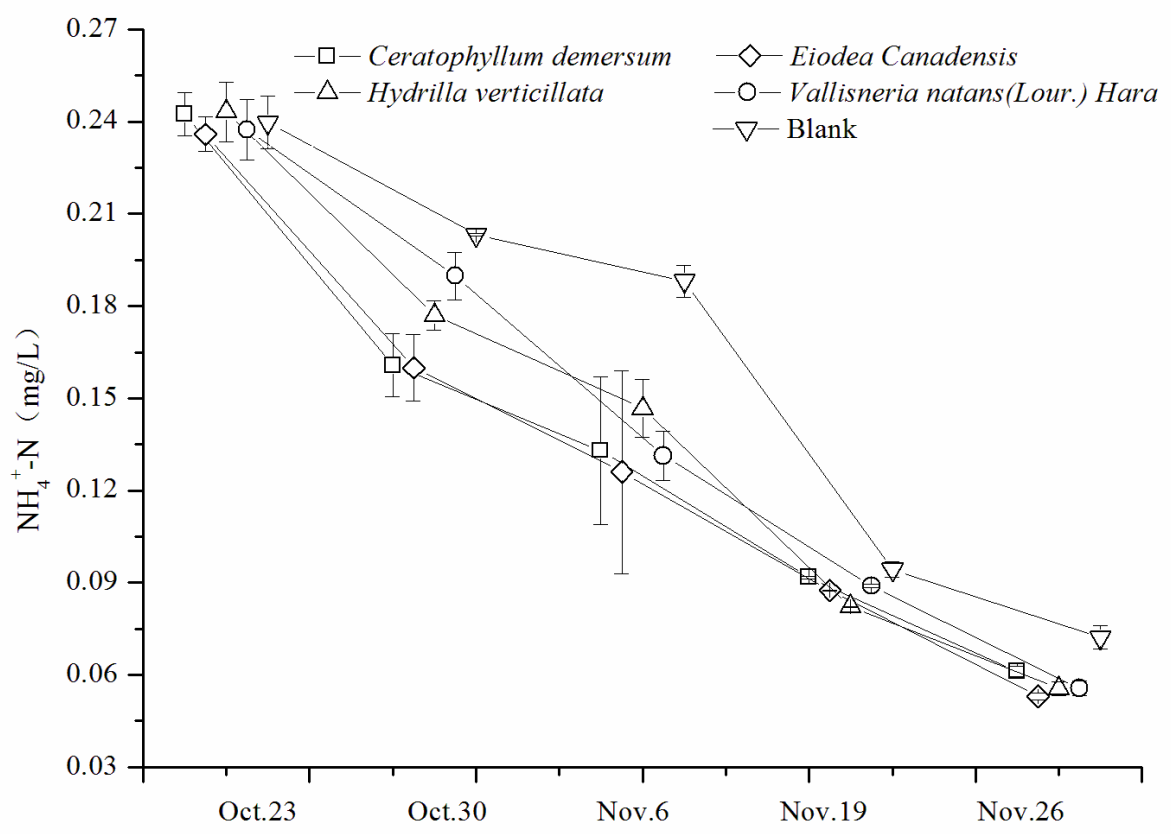

Figure 6. Variation of $\mathrm{NH} 4+-\mathrm{N}$ concentration during the experiment 


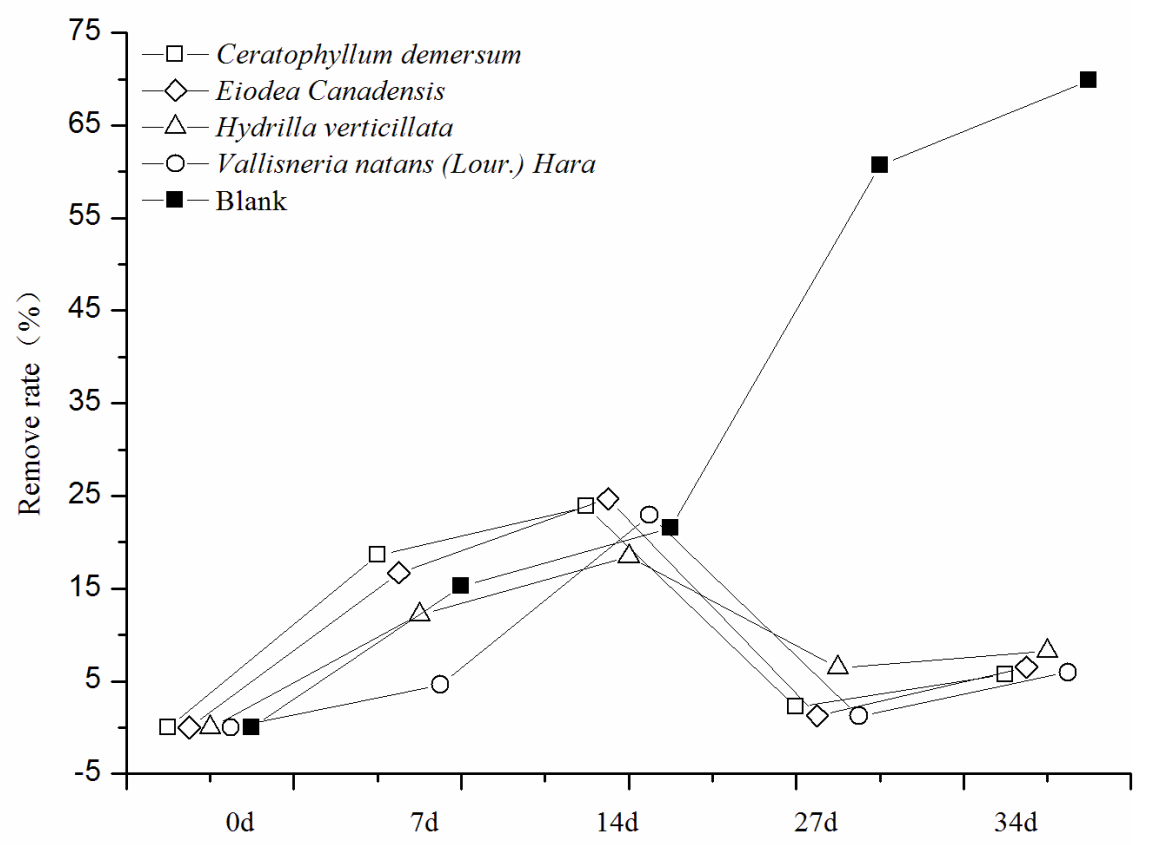

Figure 7. Removal efficiency of NH4+-N during the experiment

\section{$\mathrm{NO}_{3}-\mathrm{N}$ removal efficiency of submerged macrophytes}

During the experiments (Fig.8), $\mathrm{NO}_{3}-\mathrm{N}$ concentrations found under submerged macrophyte conditions were lower than those of the control condition. The submerged macrophyte experimental showed a decreasing tendency. However, the Vallisneria natans (Lour.) experimental conditions showed an increasing trend by the end of the experiment. $\mathrm{NO}_{3}-\mathrm{N}$ concentrations increased gradually under the control conditions (Fig.9), reaching a final value of $26.89 \%$. The removal efficiency values were calculated as the difference between the experiment with and without submerged macrophyte, which initially increased and then declined. The $\mathrm{NO}_{3}-\mathrm{N}$ removal efficiencies of Ceratophyllum demersum, Elodea canadensis, Hydrilla verticillata, and Vallisneria natans (Lour.) were 46.69\%, 41.08\%, 34.19\%, and 36.32\%, respectively. Thus, the removal efficiency levels of the four submerged macrophyte species in descending order are as follows: Ceratophyllum demersum, Elodea canadensis, Vallisneria natans (Lour.) and Hydrilla verticillata.

\section{$\mathrm{PO}_{4}-\mathrm{P}$ removal efficiency of submerged macrophytes}

The submerged macrophytes shows strong removal capabilities with $\mathrm{PO}_{4}-\mathrm{P}$ removal, and shows decreasing tendencies in the first 27 days, increases thereafter because of the dead submerged macrophytes and restrict temperatures. In the control experiments, the concentrations of $\mathrm{PO}_{4}-\mathrm{P}$ decreasd during the experiments with the terminal data found to be higher for every period. (Fig.10)

The $\mathrm{PO}_{4}-\mathrm{P}$ removal efficiency levels initially increased but then followed a decreasing tendency. The $\mathrm{PO}_{4}-\mathrm{P}$ removal rates were velatively low, and the removal efficiency attained a maximum value on the $7^{\text {th }}$ day. The removal efficiencies of Ceratophyllum demersum, Elodea canadensis, Hydrilla verticillata, and Vallisneria natans (Lour.) were $16.41 \%, 13.52 \%, 2.18 \%$, and $8.71 \%$. Thus, the removal efficiency 
levels for the four submerged macrophyte species in descending order are as follows: Ceratophyllum demersum, Elodea canadensis, Vallisneria natans (Lour.) and Hydrilla verticillata. During the experiment, the removal rate of $\mathrm{PO}_{4}-\mathrm{P}$ was even negative (Fig.11). This may be caused by the disturbance of the sampling or by the adsorption and rerelease from the sediment.



Figure 8. Variation of $\mathrm{NO}_{3}-\mathrm{N}$ concentration during the experiment

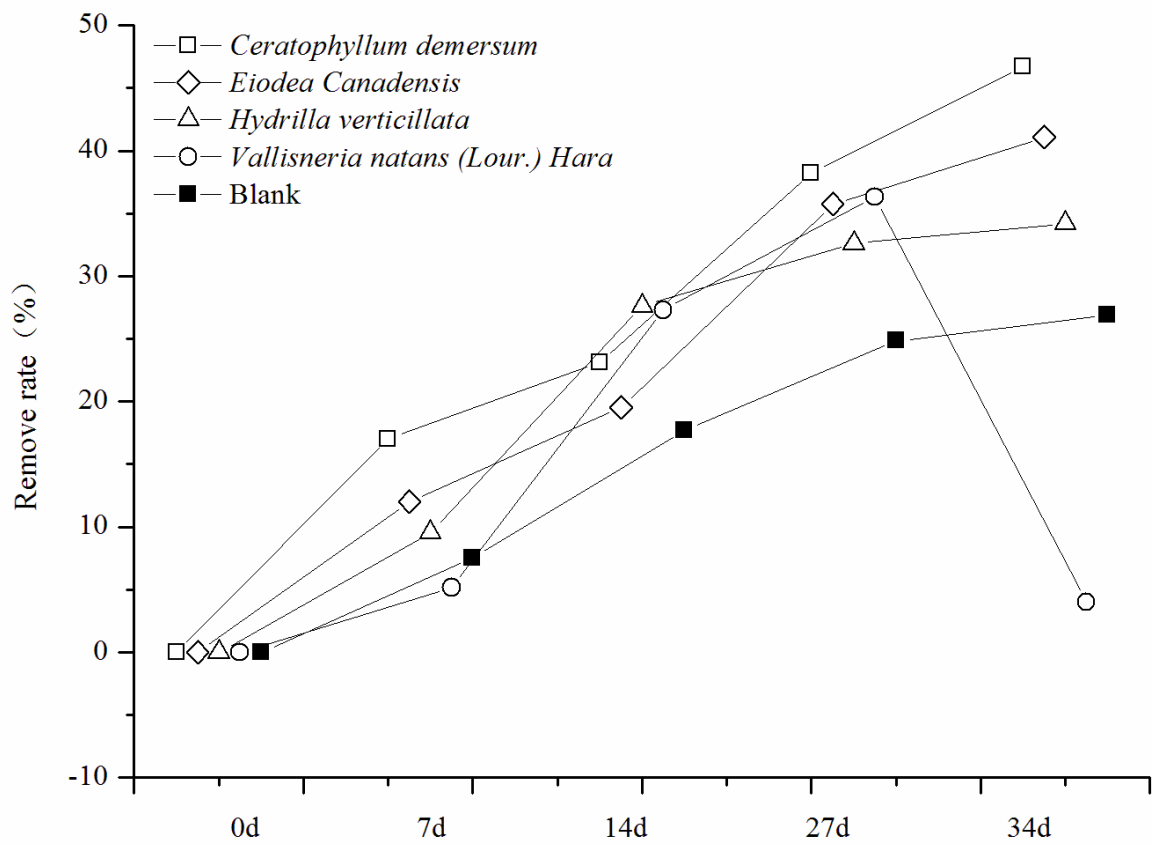

Figure 9. Removal efficiency of $\mathrm{NO}_{3}-\mathrm{N}$ during the experiment

APPLIED ECOLOGY AND ENVIRONMENTAL RESEARCH 14(2): 107-124. http://www.aloki.hu • ISSN 15891623 (Print) • ISSN 17850037 (Online) DOI: http://dx.doi.org/10.15666/aeer/1402_107124 (c) 2016, ALÖKI Kft., Budapest, Hungary 


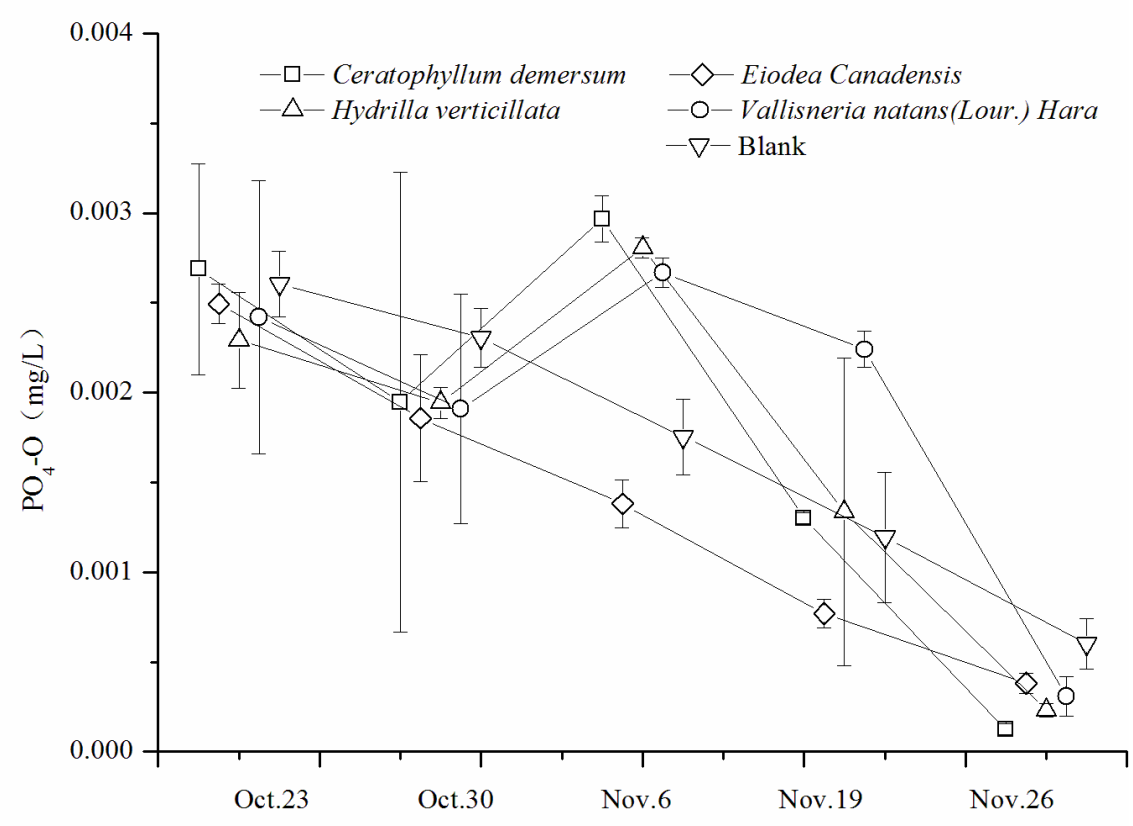

Figure 10. Variation of $\mathrm{PO}_{4}-\mathrm{P}$ concentration during the experiment

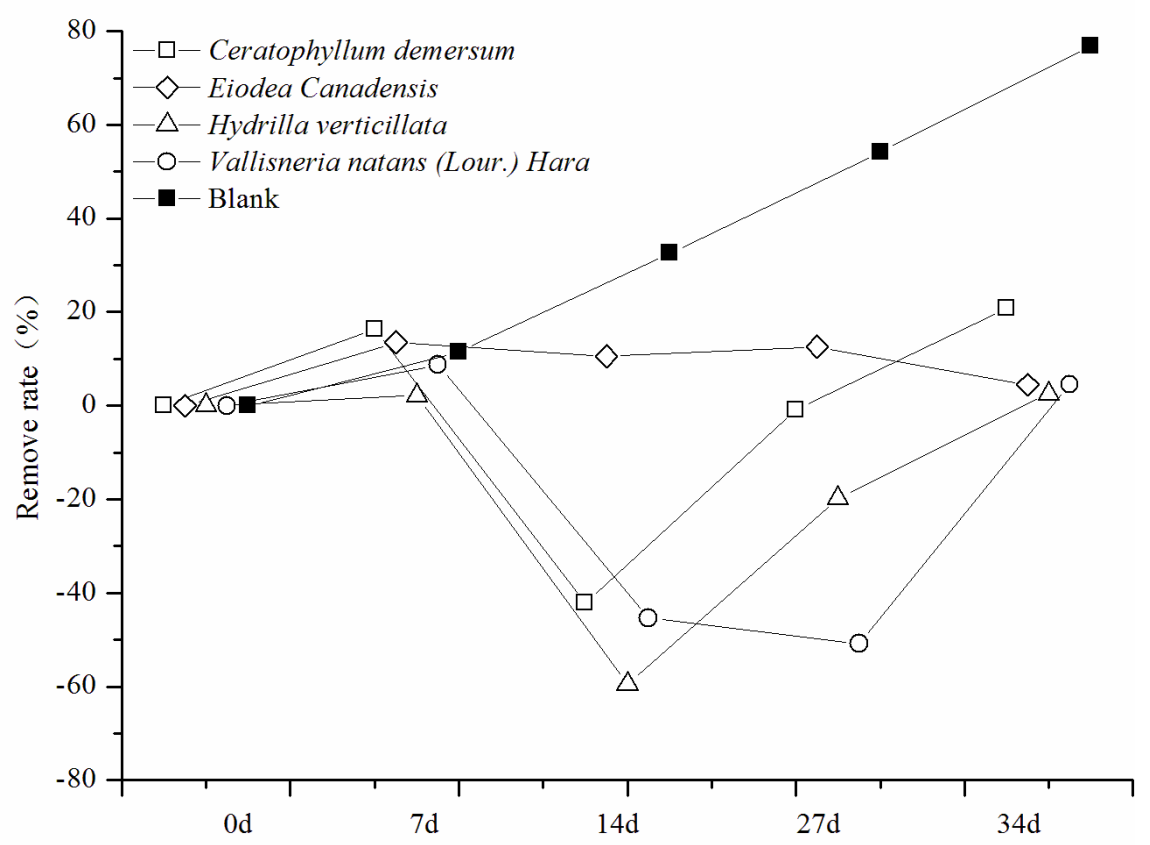

Figure 11. Removal efficiency of $\mathrm{PO}_{4}-\mathrm{P}$ during the experiment

\section{$C O D_{M n}$ removal efficiency of submerged macrophytes}

The submerged macrophytes effectively removed $\mathrm{COD}_{\mathrm{Mn}}$ from eutrophic water, as shown in Fig.12. While water was purified under the submerged macrophyte and control conditions via different ways, the submerged macrophyte conditions were much more effective than the control conditions in the experiment. 


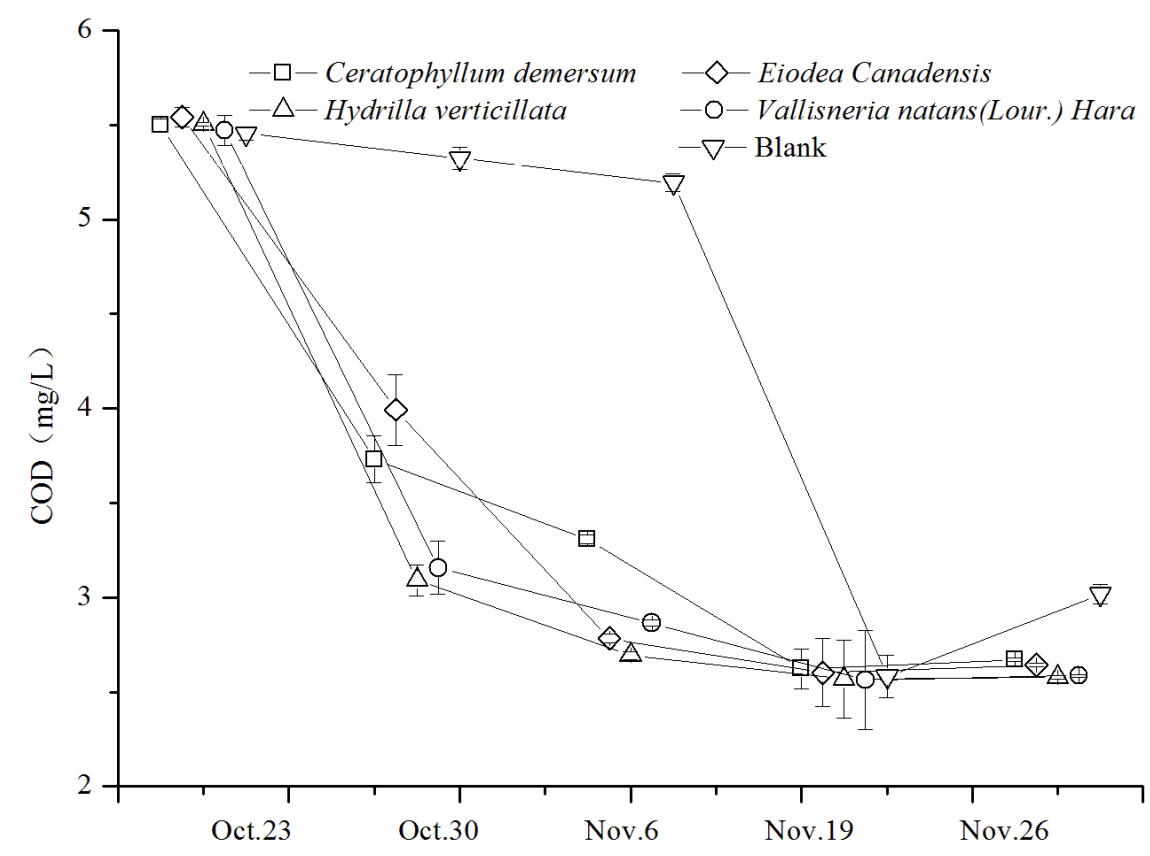

Figure 12. Variation of COD concentration during the experiment

Fig.13 presents $\mathrm{COD}_{\mathrm{MN}}$ removal efficiency levels under the control and submerged macrophyte conditions. Initially, the macrophytes exhibited strong removal capabilitieswith $\mathrm{COD}_{\mathrm{MN}}$ removal efficiencies increasing until reaching a maximum value on the $14^{\text {th }}$ day. The removal efficiencies of Ceratophyllum demersum, Elodea canadensis, Hydrilla verticillata, and Vallisneria natans (Lour.) were $35.11 \%, 45.06 \%$, $46.30 \%$, and $42.88 \%$. Thus, the removal efficiency levels for the four submerged macrophyte species in descending order are as follows: Hydrilla verticillata, Elodea canadensis, Vallisneria natans (Lour.) and Ceratophyllum demersum. Slight differences in the removal efficiency levels were found between Hydrilla verticillata and Elodea canadensis. From the $14^{\text {th }}$ to the $34^{\text {th }}$ day of the experiment, all submerged macrophyte removal efficiencies decreased, which was in agreement with the results from ChangHua Tong's (2008).

\section{The nutrient removal efficiency of submerged macrophytes}

The calculated removal capacities of Ceratophyllum demersum, Elodea canadensis, Hydrilla verticillata, and Vallisneria natans (Lour.) are shown in Table 3.

Table 3. The nutrient removal capacity characters of four types submerged macrophytes

\begin{tabular}{ccccccc}
\hline \multirow{2}{*}{ Submerged macrophytes } & \multicolumn{6}{c}{ Removal capacity } \\
& $\mathrm{TN}$ & $\mathrm{TP}$ & $\mathrm{NH}_{4}{ }^{-} \mathrm{N}$ & $\mathrm{NO}_{3}-\mathrm{N}$ & $\mathrm{PO}_{4}-\mathrm{P}$ & $\mathrm{COD}$ \\
\hline Ceratophyllum demersum & 0.7169 & 0.0199 & 0.1260 & 0.24098 & 0.00123 & 4.57445 \\
Elodea canadensis & 1.0853 & 0.0480 & 0.1670 & 0.25517 & 0.00143 & 6.00492 \\
Hydrilla verticillata & 1.0850 & 0.0417 & 0.1325 & 0.31357 & 0.00022 & 10.1771 \\
Vallisneria natans (Lour.) & 0.1540 & 0.0070 & 0.0162 & 0.04104 & 0.00013 & 1.2980 \\
\hline
\end{tabular}




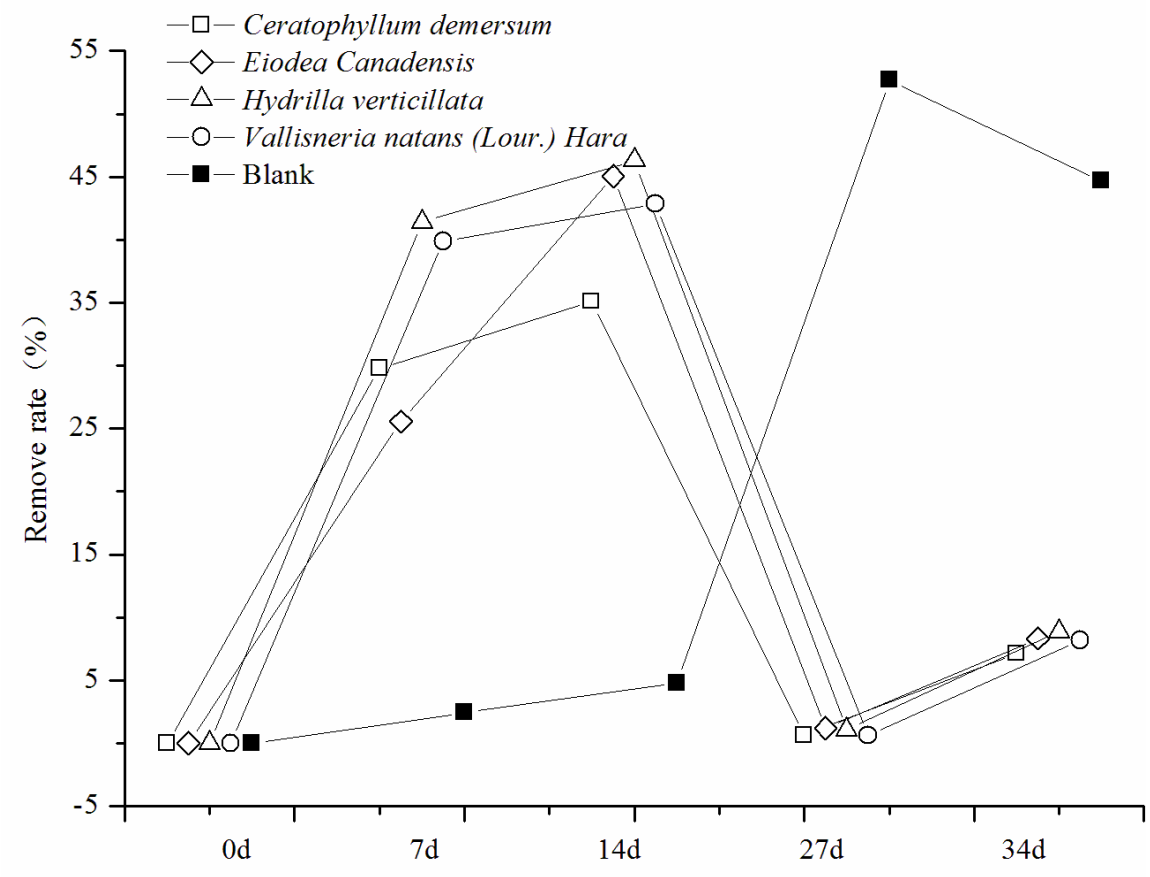

Figure 13. Removal efficiency of COD during the experiment

TN-removal efficiency levels for the four submerged macrophyte species in descending order are as follows: Elodea canadensis, Hydrilla verticillata, Ceratophyllum demersum and Vallisneria natans (Lour.).

TP-removal efficiency levels for the four submerged macrophyte species in descending order are as follows: Elodea canadensis, Hydrilla verticillata, Ceratophyllum demersum and Vallisneria natans (Lour.).

$\mathrm{NH}_{4}{ }^{+}-\mathrm{N}$-removal efficiency levels for the four submerged macrophyte species in descending order are as follows: Elodea canadensis, Hydrilla verticillata, Ceratophyllum demersum and Vallisneria natans (Lour.).

$\mathrm{NO}_{3}$-N-removal efficiency levels for the four submerged macrophyte species in descending order are as follows: Hydrilla verticillata, Elodea canadensis, Ceratophyllum demersum and Vallisneria natans (Lour.).

$\mathrm{PO}_{4}$-P-removal efficiency levels for the four submerged macrophyte species in descending order are as follows: Elodea canadensis, Ceratophyllum demersum, Hydrilla verticillata and Vallisneria natans (Lour.).

COD-removal efficiency levels for the four submerged macrophyte species in descending order are as follows: Hydrilla verticillata, Elodea canadensis, Ceratophyllum demersum and Vallisneria natans (Lour.).

Genreally, Elodea canadensis and Hydrilla verticillata exhibited higher purification capacities than the other two submerged macrophytes. Ceratophyllum demersum performed better than Vallisneria natans (Lour.), which performed the worst because it was influenced by low temperatures. 


\section{Discussion}

These four submerged macrophyte species had various degrees of low-temperature tolerance levels. Ceratophyllumdemersum $L$ resisted low temperatures most effectively, followed in descending order by Elodea canadensis, Hydrilla verticillata, and Vallisneria natans (Lour.). Therefor, by the end of the experiments, the Ceratophyllum demersum sample had grown considerably, parts of the Hydrilla verticillata sample had died, and the Vallisneria natans (Lour.) samples had almost died entirely.

Different submerged macrophytes exhibit varying $\mathrm{N}$ and $\mathrm{P}$ absorption capacities. A study (Shen et al., 2005) showed that Ceratophyllum demersum, Elodea canadensis, and Vallisneria natans (Lour.) improve aquatic quality in a descending order of Elodea canadensis, Ceratophyllum demersum, and Vallisneria natans (Lour.). The present study arrived at the same conclusion. This phenomenon also occurred with respect to Nitrogen-Phosphate absorption (Shan and Luo, 2008), which produced various removal rates. According to the results, submerged macrophytes played an important role in removing nitrogen, phosphate, nutrient salts, etc., from eutrophic water. The removal rates were recorded at approximately $35 \%-70 \%$, except for the case of $\mathrm{N}$ and $\mathrm{P}$ removal. We present the following findings: 1) The TN removal percentages for Ceratophyllum demersum, Elodea canadensis, Hydrilla verticillata, and Vallisneria natans (Lour.) were $67.84 \%, 68.70 \%, 64.38 \%$, and $69.13 \%$, respectively. The TN removal efficiency levels for the four submerged macrophyte species a in descending order were as follows: Vallisneria natans (Lour.), Elodea canadensis, Ceratophyllumdemersum L, and Hydrilla verticillata. 2) The TP removal rates for Ceratophyllum demersum, Elodea canadensis, Hydrilla verticillata, and Vallisneria natans (Lour.) were 36.59\%, 58.60\%, $47.94 \%$, and $43.70 \%$, respectively. The removal efficiency levels for the four submerged macrophyte species in descending order were as follows Elodea canadensis, Hydrilla verticillata, Vallisneria natans (Lour.), and Ceratophyllum demersum 3) The $\mathrm{NH}_{4}{ }^{+}-\mathrm{N}$ removal percentages for Ceratophyllum demersum, Elodea canadensis, Hydrilla verticillata, and Vallisneria natans (Lour.) were $23.86 \%, 24.69 \%, 18.47 \%$, and $22.93 \%$, respectively. Thus the removal efficiency levels for the four submerged macrophyte species in descending order are as follows: Elodea canadensis, Ceratophyllum demersum, Vallisneria natans (Lour.), and Hydrilla verticillata. 4) the $\mathrm{NO}_{3}-\mathrm{N}$ removal efficiencies of Ceratophyllum demersum, Elodea canadensis, Hydrilla verticillata, and Vallisneria natans (Lour.) were 46.69\%, 41.08\%, 34.19\% and 36.32\%, respectively. Thus the removal efficiency levels for the four submerged macrophyte species in descending order are as follows: Ceratophyllum demersum, Elodea canadensis, Vallisneria natans (Lour.), and Hydrilla verticillata. 5) the removal efficiencies of Ceratophyllum demersum, Elodea canadensis, Hydrilla verticillata, and Vallisneria natans (Lour.) were $16.41 \%, 13.52 \%, 2.18 \%$, and $8.71 \%$. Thus, the removal efficiency levels for the four submerged macrophyte species in descending order are as follows: Ceratophyllum demersum, Elodea canadensis, Vallisneria natans (Lour.) and Hydrilla verticillata. 6) The COD removal efficiencies of Ceratophyllum demersum, Elodea canadensis, Hydrilla verticillata, and Vallisneria natans (Lour.) were $35.11 \%$, $45.06 \%, 46.30 \%$, and $42.88 \%$, respectively. Thus the removal efficiency levels for the four submerged macrophyte species in descending order are as follows: Hydrilla verticillata, Elodea canadensis, Vallisneria natans (Lour.), and Ceratophyllum demersum

Submerged macrophyte canopies significantly affected photosynthesis outcomes. Of the four submerged macrophyte species, photosynthesis outcomes generated by 
Ceratophyllum demersum were less significant due to underwater conditions. Due to the low temperatures, Ceratophyllum demersum grew slowly and polluted the water sample due to degradation, thus generating the lowest removal capacity result. Under low temperature conditions, different submerged macrophytes exhibited varying removal capacities. Therefore, We conclude the following: 1) The TN removal efficiency levels for the four submerged macrophyte species in descending order are as follows: Elodea canadensis, Hydrilla verticillata Ceratophyllum demersum and Vallisneria natans (Lour.). 2) The TP removal efficiency levels for the four submerged macrophyte species in descending order are as follows: Elodea canadensis, Hydrilla verticillata Ceratophyllum demersum and Vallisneria natans (Lour.). 3) The $\mathrm{NH}_{4}{ }^{+}-\mathrm{N}$ removal efficiency levels for the four submerged macrophyte species in descending order are as follows: Elodea canadensis, Hydrilla verticillata, Ceratophyllum demersum and Vallisneria natans (Lour.). 4) The $\mathrm{NO}_{3}-\mathrm{N}$ removal efficiency levels for the four submerged macrophyte species in descending order are as follows: Hydrilla verticillata, Elodea canadensis, Ceratophyllum demersum and Vallisneria natans (Lour.). 5) The $\mathrm{PO}_{4}-\mathrm{P}$ removal efficiency levels for the four submerged macrophyte species in descending order are as follows: Elodea canadensis, Ceratophyllum demersum, Hydrilla verticillata and Vallisneria natans (Lour.). 6) The COD removal efficiency levels for the four submerged macrophyte species in descending order are as follows: Hydrilla verticillata, Elodea canadensis, Ceratophyllum demersum and Vallisneria natans (Lour.).

\section{Conclusion}

Based on the growth conditions, nutrient removal rates and removal capacities of the four submerged macrophyte species examined, under low temperature conditions, Elodea canadensis and Hydrilla verticillata more effectively removed nutrient salts, while Ceratophyllum demersum and Vallisneria natans (Lour.) were less effective. Therefore, Elodea canadensis and Hydrilla verticillata could be employed for aquatic system ecological repair and water pollution control in the Poyang Lake basin, especially in aquaculture areas.

Acknowledgements. Thanks are extended to Jiangxi Provincial Key Laboratory of Water Resources and Environment of Poyang Lake for providing the foundation for the experiment. This study was financially supported by the National Basic Research Program of China (grant 2012CB417006), Fund for Less Developed Regions of the National Natural Science Foundation of China (grant 51369011), National Youth Science Found Project (grant 51409133) and Science and Technology Project of Jiangxi Province (grant KT201210, KT201406, KT201503, KT201504, KT201510).

\section{REFERENCES}

[1] Bin, Z, Christine, M. M, Lars, G. R, Edward, L. M, Mark, E. R. 2008. A comparison of irradiance and phosphorus effects on the growth of three submerged macrophytes. Aquatic Botany 88: 358 -362.

[2] Blindow, I., Hargeby, A., Andersson, G., 2002. Seasonal changes of mechanisms maintaining clear water in a shallow lake with abundant Chara vegetation. - Aquatic Botany 72: 315-334. 
[3] Bole, J.B. and Allan, J.R., 1978. Uptake of phosphorus from sediment by aquatic plants, Myriophyllum spicatum and Hydrilla verticillata. - Water Res. 12: 353-358.

[4] Carpenter, S. R. (2008): Phosphorus control is critical to mitigating eutrophication. National Acad Sciences 105: 11039-11040.

[5] Cedergreen, N. (2003): Nitrate reductase activity in roots and shoots of aquatic macrophytes. - Aquatic Botany 76: 203-212.

[6] Ewell, J. J. (1987): Restoration is the ultimate test of ecological theory. In: Jordan, W. R., Gilpin, M. E., Aber, J. D. (eds.) Restoration Ecology. Cambridge University Press, UK. pp. 31-33.

[7] Guan, S. F., Lang, Q., Zhang, B. (1987): Biomass of macrophytes of the Poyang Lake with suggestions of its rational exploitation. - Acta Hydrobiological Sinica 11: 219 - 227.

[8] Hautier, Y., Niklaus, P. A., Hector, A. (2009): Competition for light causes plant biodiversity loss after eutrophication. - Science 324: 636-638.

[9] Howarth, R. W. and Marino, R. (2006): Nitrogen as the limiting nutrient for eutrophication in coastal marine ecosystems: evolving views over three decades. Limnology and Oceanography 51: 364-376.

[10] Hu, Y., Wei, Z., Hong, J. (2008): Research on the deep treatment effect of several submerged plants on domestic sewage under low temperature. - Journal of Anhui Agri. Sci 36: 1573-1575.

[11] Huang, L., Zhai, J. P.,Wang, C. Y., Nie, R., Yuan, D. H. (2005): Removals of nitrogen and phosphorus in Taihu Lake water by four hydrophytes in winter season. - Journal of Agro-Environment Science 24: 366-370.

[12] Huang, L., Zhai, J. P., Nie, R., Wang, C. Y., Jiang, X. Y. (2005): Experimental study of decontamination and resistance ability of five hydrophytes. - Research of Environmental Science, 18: 33-38.

[13] Jin, X. C., Tu, Q. Y. (1990): Rules of eutrophication invesgation in lake. - China Environmental Science Press, Beijing.

[14] Li, K. and Hu, Z. (1995): Mechanisms of sewage purification by reed bed system. China Environmental Science 15: 140-144.

[15] Phillips, G.L., Eminson, D., Moss, B. (1978): A mechanism to account for macrophyte decline in progressively eutrophicated freshwaters. - Aquatic Botany 4: 2103-2126.

[16] Reddy, K. R., Kebusk, T. A. (1987): State of the art utilization of aquatic macrophytes inwaterpollution control. - Wat Sci Tech 19: 61-79.

[17] Ren, W. J., Tian, Z. F., Ning, G. H. Liu, X. Hu, X. B. Xie, J. Z. (2011): Purification efficiency of four species submerged macrophytes for the eutrophic water in Baiyangdian Lake. - Ecology and Environmental Sciences 20: 345-352.

[18] Shan, D., Luo, A. (2008): Phosphorus uptake characteristics of six aquatic plants. - Acta Agriculture Zhejiangensis 20: 135-138.

[19] Shen, Y. L., Wang, M. J., Li, Y., Zhang, W. J., Fei, Z. M., Luo, L., Huang, Y. (2005): Research on Purification Efficiency of Polluted Water Remediation by Submerged Macrophytes. - Journal of University of Science and Technology of Suzhou (Engineering and Technology) 18: 1-4.

[20] Song, F., Chen, Y. Q. (1997): Study on the Removal Rate to Total Nitrogen in Caohai Lake (Including Sediments) by Common Submerged Macrophytes. - Research of Environmental Science 1:47-50.

[21] Sun, Z. D., Song, X. P., Fu, Z. S., He, W. H., Wang, J. Q., Liu, F. X., Shang, C L, Song, F F. (2012): Water purification capacity of different submerged plants. - Acta Agriculturae Shanghai 28: 30-35.

[22] Tian, Q., Wang, P. F., Ouyang, P. Wang, C. Zhang, W. M. (2009): Purification of eutrophic water with five submerged hydrophytes. - Water resources protection 25:14-17.

[23] Tong, C. H., Yang, X. E., Pu, P. M. (2004): Purification of eutrophicated water by aquatic plant. - Chinese Journal of Applied Ecology 15: 1448-1450. 
[24] Wang, L. Q., Li, Y., Zhang, R. L. (2008): The Purification of Lake Dianshan Water Quality with Six Species of Submerged Macrophyte Systems. - Journal of AgroEnvironment Science 27: 1134-1139.

[25] Wang, S. R., Jin, X. C., Zhao, H. C., Wu, F. C. (2008): Phosphate biosorption characteristics of a submerged macrophyte Hydrilla verticillata. - Aquatic Botany 89: 2326

[26] Wigand, C., Stevenson, J. C., Cornwell, J. C. (1997): Effects of different submersed macrophytes on sediment biogeochemistry. - Aquatic Botany 56: 234.

[27] Zhang, J., Shao, W. S., He, M., Hu, H. Y., Gao, B. Y. (2006): Treantment performance and enhancement of subsurface constructed wetland treating polluted river water in winter. - Environmental Science 27: 1560-1564.

[28] Zhao, A. N., Feng, M. H., Li, W. C., Pan, J. Z., Ke, F. (2010): Effect of photosynthesis oxygen evolution of submerged macrophyte Elodea nuttallii on nitrogen transformation in water. - Ecology and Environmental Sciences 19: 757-761.

\section{ELECTRONIC APPENDIX}

This article has an electronic appendix with basic data. 